\title{
New Approach to the $\beta \rightarrow \alpha$ Polymorphic Transformation in Magnesium-Substituted Tricalcium Phosphate and its Practical Implications
}

\author{
Raúl García Carrodeguas, ${ }^{\ddagger}$ Antonio H. De Aza, ${ }^{\S}$ Xavier Turrillas, " Pilar Pena ${ }^{\S}$, and Salvador De Aza ${ }^{\dagger, \S, * \star}$ \\ ${ }^{\ddagger}$ Centro de Biomateriales, Universidad de La Habana, La Habana 10400, Cuba \\ ${ }^{\S}$ Departamento de Cerámica, Instituto de Cerámica y Vidrio, CSIC, Madrid 28049, Spain \\ "Departamento Química-Física, Instituto de Ciencias de la Construcción \\ "Eduardo Torroja," CSIC, Madrid 28033, Spain
}

\begin{abstract}
The transformation $\beta \rightarrow \alpha$ in Mg-substituted $\mathrm{Ca}_{3}\left(\mathrm{PO}_{4}\right)_{2}$ was studied. The results obtained showed that, contrary to common belief, there is, in the system $\mathrm{Mg}_{3}\left(\mathrm{PO}_{4}\right)_{2}-\mathrm{Ca}_{3}\left(\mathrm{PO}_{4}\right)_{2}$, a binary phase field where $\beta+\alpha-\mathrm{Ca}_{3}\left(\mathrm{PO}_{4}\right)_{2}$ solid solutions coexist. This binary field lies between the single-phase fields of $\beta$ - and $\alpha-\mathrm{Ca}_{3}\left(\mathrm{PO}_{4}\right)_{2}$ solid solution in the $\mathrm{Ca}_{3}\left(\mathrm{PO}_{4}\right)_{2}$-rich zone of the mentioned system. In the light of the results and the Palatnik-Landau's Contact Rule of Phase Regions, a corrected phase equilibrium diagram has been proposed. The practical implications of these findings with regard to the synthesis of pure $\alpha$ - and $\beta$ - Mg-substituted $\mathrm{Ca}_{3}\left(\mathrm{PO}_{4}\right)_{2}$ powders and to the sintering of related bioceramics with improved mechanical properties are pointed out.
\end{abstract}

\section{Introduction}

$\mathrm{N}$ OWADAYs tricalcium phosphate $\left(\mathrm{Ca}_{3}\left(\mathrm{PO}_{4}\right)_{2}\right.$, namely in short TCP) is one of the most important calcium phosphatebased biomaterials because of its biocompatibility, in vivo bioactivity, bioresorbability, and osteoconductivity. There are three polymorphs of TCP ${ }^{1}$ the low temperature, $\beta$-TCP, and the high temperature forms, $\alpha$ - and $\alpha^{\prime}$-TCP. The last one lacks of practical interest because only exists at temperatures above $\sim 1430^{\circ} \mathrm{C}$ and reverts to $\alpha$-TCP by cooling below the transition temperature. However, $\beta$-TCP is stable at room temperature and transforms reconstructively $y^{2,3}$ at $\sim 1125^{\circ} \mathrm{C}$ to $\alpha$-TCP, which can be retained during cooling to room temperature. Both are currently used in several clinical applications in dentistry, maxilla-facial, and orthopedics; $\beta$-TCP is the component of several commercial mono- or biphasic bioceramics and composites and $\alpha$-TCP is the major constituent of powder component of various hydraulic bone cements. ${ }^{4,5}$

Magnesium is a very common impurity in commercially available calcium compounds used as precursors in the synthesis of biomedical grade calcium phosphates. Therefore, laboratory made TCPs often contain a few tenths percent of $\mathrm{Mg}$, which exerts a remarkable effect on the phase equilibrium relationships of the $\beta$ and $\alpha$ polymorphs.

According to the early work by Ando, ${ }^{6}$ a narrow field of Mg-substituted TCP $\left(\mathrm{Ca}_{3-x} \mathrm{Mg}_{x}\left(\mathrm{PO}_{4}\right)_{2}\right.$, namely TCPss in short)

P. Brown—contributing editor

\footnotetext{
Manuscript No. 23726. Received September 10, 2007; approved December 3, 2007. This work was supported by Science and Technology Inter-Ministry Commission of Spain under project CICYT MAT2006-12749-C02-01 and by State Secretary of universities and Research of the Ministry of Education and Science of Spain under Grant SAB20050015. Beam time was granted by Institut Max von Laue-Paul Langevin (ILL), Collaborating Research Group D1B (CSIC/CICYT-CNRS), Grenoble, France, Exp. No. CRG-9322.

${ }^{* *}$ Fellow, the American Ceramic Society.

'Present address: Instituto de Cerámica y Vidrio, CSIC, Madrid 28049, Spain. ${ }^{\dagger}$ Author to whom correspondence should be addressed. e-mail: aza@icv.csic.es
}

exists at the TCP-rich region in the phase equilibrium diagram of the system $\mathrm{Mg}_{3}\left(\mathrm{PO}_{4}\right)_{2}-\mathrm{Ca}_{3}\left(\mathrm{PO}_{4}\right)_{2}$. The maximum solubility of 13.2 at. $\%$ of $\mathrm{Mg}$ is reached at $1175^{\circ} \mathrm{C}$, and the temperature of the $\beta \rightarrow \alpha$ transformation is shifted from $1180^{\circ} \mathrm{C}$ for pure TCP to $1485^{\circ} \mathrm{C}$ for $4.1 \mathrm{Mg}$ at. $\%$ containing TCPss. The phase equilibrium diagram proposed by Ando ${ }^{6}$ has been recently revisited by Enderle et al. ${ }^{7}$ who redrew the $\beta \rightarrow \alpha$ transformation temperature curve as a function of the at. $\%$ of $\mathrm{Mg}$ content in the TCP-rich zone (Fig. 1). However, according to Ando ${ }^{6}$ and Enderle et al., ${ }^{7}$ the boundary between the field of the low temperature $\beta$-TCPss and the high temperature $\alpha$-TCPss is a line (one-dimension), which contradicts Palatnik-Landau's Contact Rule of Phase Regions (CRPR), ${ }^{8-11}$ lately reformulated by Zhao et al. ${ }^{12}$ as the Boundary Theory (BT). As stated by the CRPR and the BT a phase boundary line (one-dimension) cannot separate two mono-phase fields in a binary phase equilibrium diagram at constant pressure.

On the other hand, several reported attempts for obtaining pure $\alpha$-TCP by heating $\beta$-TCP above the expected transition temperatures, after the data of Ando and Enderle et al., and quenching to room temperature have failed, obtaining instead a mixture of $\alpha$ - and $\beta$-TCP phases. ${ }^{13,14}$. These results have been frequently misunderstood and erroneously attributed to the reversibility of the $\alpha \rightarrow \beta$ transformation, which, on the contrary, is reconstructive and requires considerably energy to proceed in fact. $^{7}$ Additionally, full densification of pure phase $\beta$-TCP ceramics has been unsuccessful up to the present because of the appearing of $\alpha$-phase at temperatures above $1125^{\circ} \mathrm{C} .^{13,15,16}$

Summarizing, the preparation of pure $\alpha$ - and $\beta$-TCP remains being a problem because of the misinterpretation of the experimental facts observed during the study of the conversion between both polymorphs. This is normally due to the influence of small amounts of impurities, such as $\mathrm{Mg}$, commonly present in the materials used in their preparation and frequently disregarded by the investigators, and the passing over well-established thermodynamic laws.

In the present work, a correction to the phase equilibrium diagram of the system $\mathrm{Mg}_{3}\left(\mathrm{PO}_{4}\right)_{2}-\mathrm{Ca}_{3}\left(\mathrm{PO}_{4}\right)_{2}$, in the TCP-rich zone, is proposed in the light of experimental data and the CRPR. Its significance in the synthesis of $\alpha$ - and $\beta$ - Mg-substituted TCP powders and in the sintering of related bioceramics with improved mechanical properties are pointed out.

\section{Experimental Procedure}

Mg-free TCP precursor (precipitated calcium-deficient apatite) was obtained from Merck (Darmstadt, Germany). Mg-doped TCP was kindly supplied by M. R. Anseau from the Department of General, Organic and Biomedical Chemistry of the University of Mons-Hainaut, Belgium. 


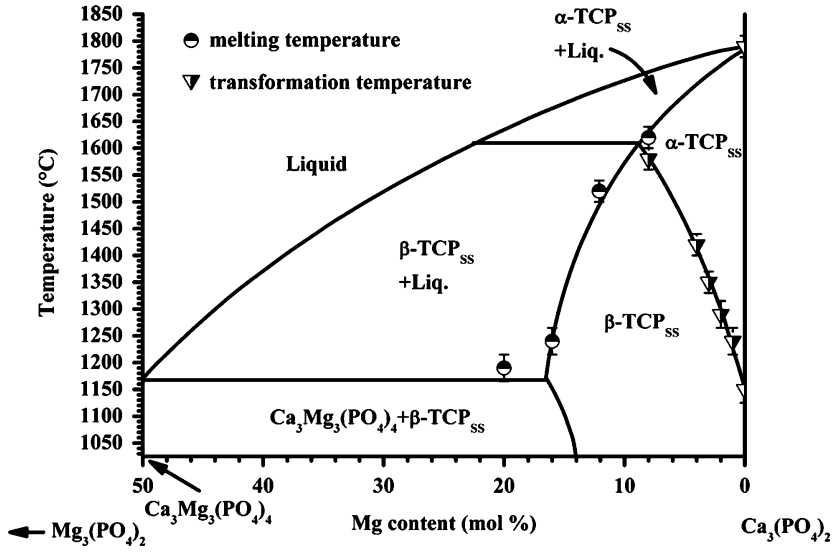

Fig. 1. Phase equilibrium diagram of the system $\mathrm{Mg}_{3}\left(\mathrm{PO}_{4}\right)_{2}-$ $\mathrm{Ca}_{3}\left(\mathrm{PO}_{4}\right)_{2}$. (Redrawn from Enderle et al.). ${ }^{7}$

Their chemical compositions were analyzed in a MagiX Super Q Version 3.0 X-ray fluorescence spectrometer (Philips Analytical, Almelo, the Netherlands) provided with an $\mathrm{Rh} \mathrm{X}$-ray tube and a power generator of $2.4 \mathrm{~kW}$. Powdered samples weighing $0.3000 \mathrm{~g}$ were mixed with $5.5 \mathrm{~g}$ of spectral grade $\mathrm{Li}_{2} \mathrm{~B}_{4} \mathrm{O}_{7}$ and melted in a $\mathrm{Pt} / \mathrm{Au}$ crucible and formed into disks in a special controlled furnace Perl'X3 (Philips). Calibration curves were prepared from standards of certified composition of natural and synthetic calcium phosphates. The results of the chemical analysis are displayed in Table $\mathrm{I}$. The $\mathrm{Mg}$ content (expressed as $\mathrm{MgO}$ ) in $\mathrm{Mg}$-doped TCP was $0.38 \pm 0.02 \mathrm{wt} \%$, equivalent to $0.97 \pm 0.05$ at. $\%$ of $\mathrm{Mg}$ substitution. Minor amounts of $\mathrm{S}, \mathrm{Al}$, $\mathrm{Na}, \mathrm{Mn}, \mathrm{Fe}, \mathrm{Sr}$, and $\mathrm{Si}$, were also found in this material. In $\mathrm{Mg}$ free TCP, the amounts of $\mathrm{Mg}$ and the other minor elements were lower than the limits of the method of determination.

Both materials consisted only of crystalline $\beta$-TCP (JCPDS card no. 9-169) after heating at $900^{\circ} \mathrm{C}$ for $2 \mathrm{~h}$ as shown in the X-ray powder diffraction patterns of Figs. 4 and 5.

High-temperature powder neutron diffraction (ND) data were collected at the Institute Laue-Langevin (Grenoble, France) with the instrument D1B, operated at a wavelength of $0.252275 \mathrm{~nm}$. A furnace was attached to the instrument to provide temperatures up to $1500^{\circ} \mathrm{C}$. Cylindrical bars of the TCP powders were isostatically pressed at $200 \mathrm{MPa}$ and introduced into a $9 \mathrm{~mm}$ of diameter and $80 \mathrm{~mm}$ length $\mathrm{Nb}$ tube. B-type (Pt30Rh/Pt6Rh) thermocouple was placed in touch with the $\mathrm{Nb}$ holder in order to measure the sample temperature with an accuracy of $\pm 2{ }^{\circ} \mathrm{C}$. The experiments were conducted in vacuum at heating and cooling rates of $10^{\circ} \mathrm{C} / \mathrm{min}$ from room temperature to $800^{\circ} \mathrm{C}$ and $5^{\circ} \mathrm{C} / \mathrm{min}$ from $800^{\circ}$ to $1500^{\circ} \mathrm{C}$. Diffraction patterns between $10^{\circ}$ and $90^{\circ}(2 \theta)$ were acquired at 1 -min intervals.

TCP disks ( $11 \mathrm{~mm}$ diameter $\times 1.5 \mathrm{~mm}$ height $)$ were shaped by uniaxial pressing in stainless-steel die at $250 \mathrm{MPa}$ and heated at $1200^{\circ}, 1300^{\circ}, 1400^{\circ}, 1500^{\circ}$, and $1600 \pm 10^{\circ} \mathrm{C}$ at $10^{\circ} \mathrm{C} / \mathrm{min}$, kept 2 $\mathrm{h}$ at the maximum temperature and then cooled to room temperature at $10^{\circ} \mathrm{C} / \mathrm{min}$. Sintered disks, manufactured as described in this paper, were used in microstructure analysis. In powder X-ray diffraction analysis, powdered samples with average particle diameter $<70 \mu \mathrm{m}$ were tested.

Powder X-ray diffraction patterns were recorded in a diffractometer D5000 (Siemens, Berlin, Germany) using radia-
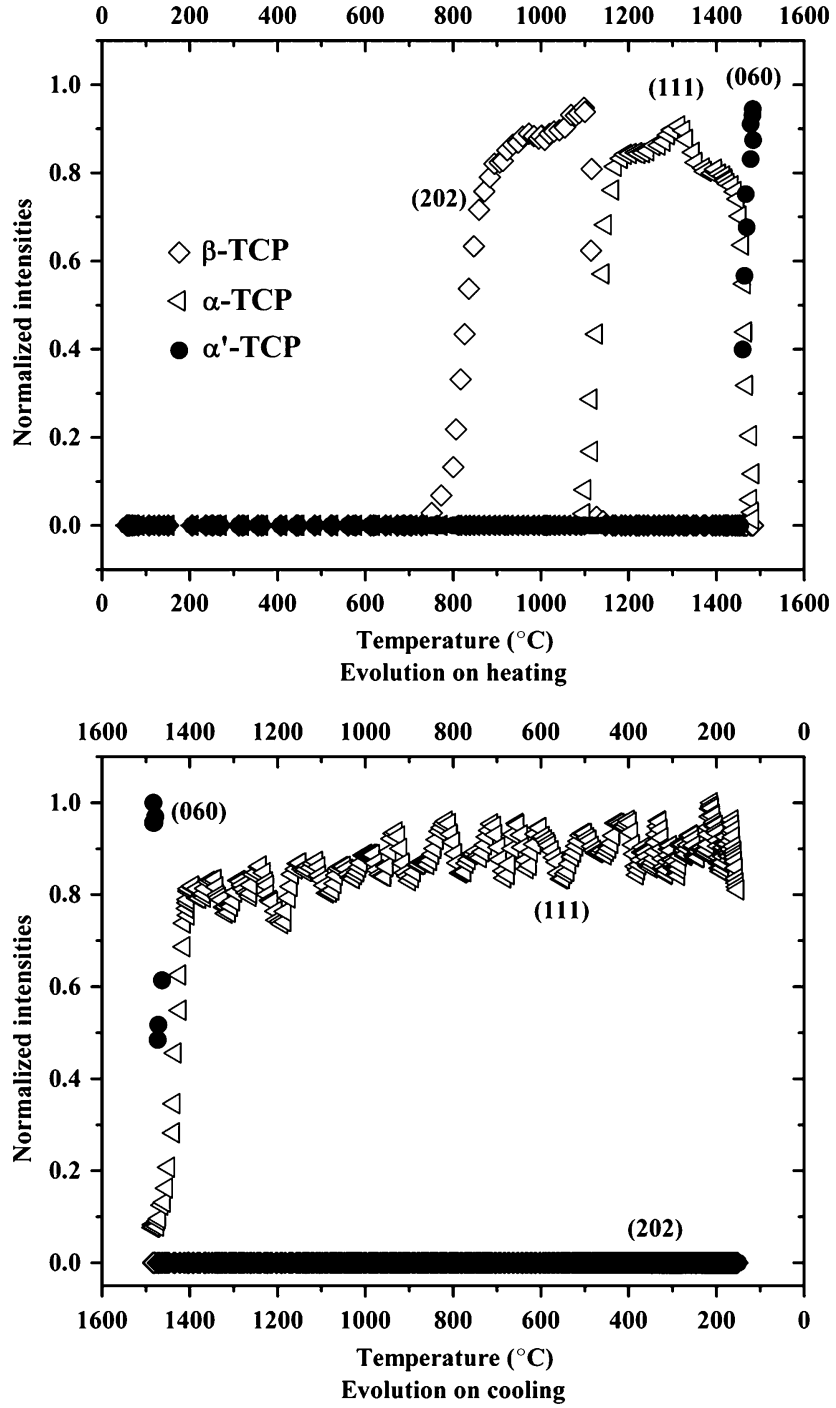

Fig. 2. Results of the real time follow-up to the evolution of crystalline tricalcium phosphate (TCP) phases during thermal treating of $\mathrm{Mg}$-free TCP by means of neutron diffraction.

tion $\mathrm{CuK} \alpha_{1,2}(0.15418 \mathrm{~nm})$ and anode operation voltage and current of $50 \mathrm{kV}$ and $30 \mathrm{~mA}$, respectively. The Bragg-Brentano geometry was used and samples were rotated at $0.25 \mathrm{~s}^{-1}$ during recording. Step size of $0.05^{\circ}$, and time/step ratio of $1.5 \mathrm{~s}$.

Microstructures of the samples sintered at different temperatures were studied by scanning electron microscopy. The TCP disks were polished with diamond paste down to $1 \mu \mathrm{m}$ and etched with diluted acetic acid (1:5) for $10 \mathrm{~s}$. After gold coating, the samples surfaces were examined in a field emission scanning electron microscope (FE-SEM) Hitachi S-4700 (Hitachi, Tokyo, Japan).

\section{Results and Discussion}

Palatnik-Landau's $\mathrm{CRPR}^{8-11}$ was applied to the $\beta$ - and $\alpha$-TCPss phase regions in the phase equilibrium diagram proposed by Enderle et al. ${ }^{7}$ (Fig. 1) using the formulism of Zhao et al. ${ }^{12}$

Table I. Results of the Chemical Analysis (X-Ray Fluorescence) of the TCPs Used in the Work

\begin{tabular}{|c|c|c|c|c|c|c|c|c|c|c|c|}
\hline TCP & \multicolumn{10}{|c|}{ Content (wt \%) } & $\mathrm{Ca} / \mathrm{P}$ \\
\hline Mg-free & $54.6(3)$ & $45.4(3)$ & b.l.a. & b.l.a. & b.l.a. & b.l.a. & b.l.a. & b.l.a. & b.l.a. & b.l.a. & $1.52(2)$ \\
\hline
\end{tabular}

\footnotetext{
Uncertainties of the last digit in parentheses. b.l.a., below the limit of determination of the analytical method; TCP, tricalcium phosphate.
} 

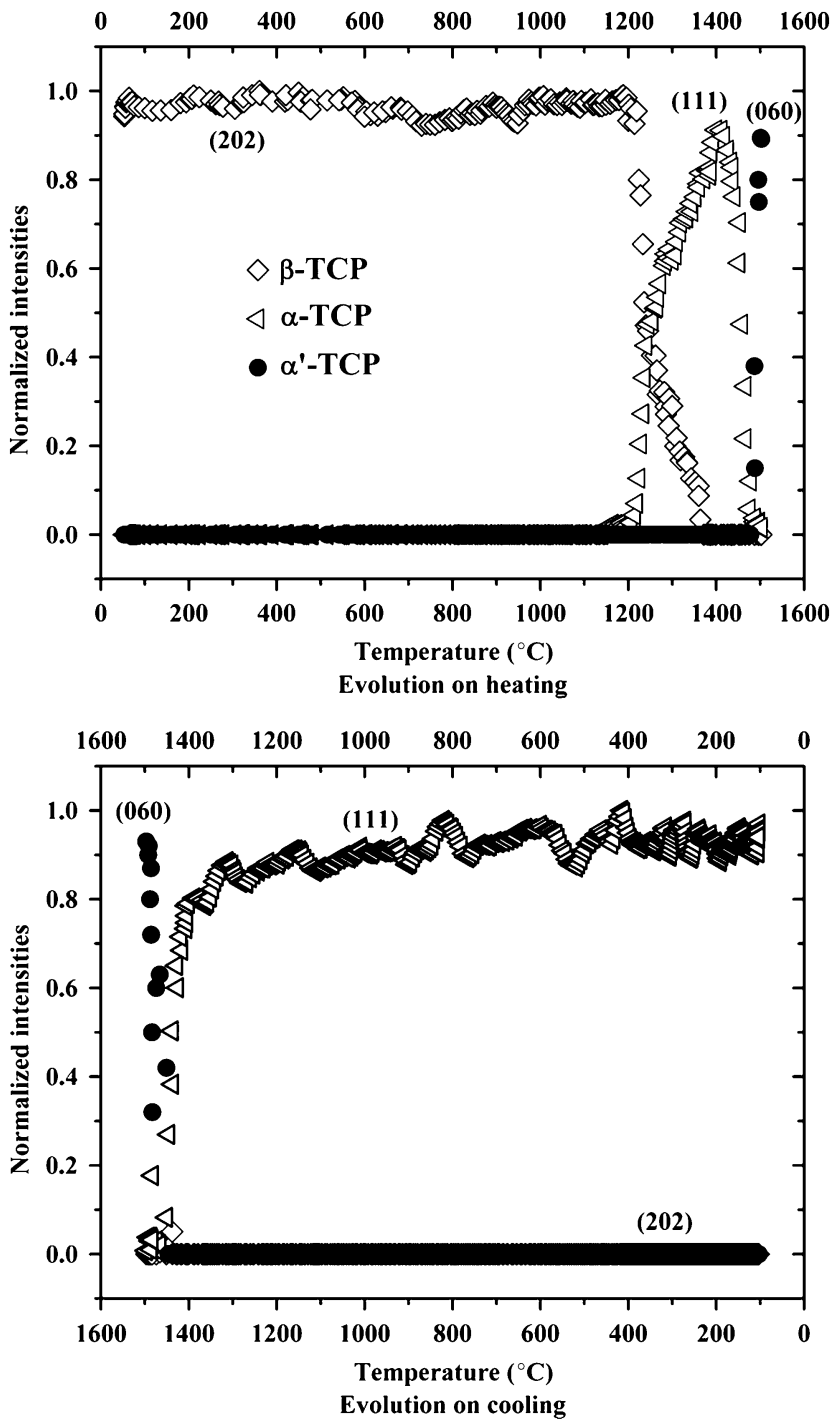

Fig. 3. Results of the real time follow-up to the evolution of crystalline tricalcium phosphate (TCP) phases during thermal treating of $\mathrm{Mg}$ doped TCP by means of neutron diffraction.

According to this, for a section of an isobaric phase diagram containing a "phase boundary," its dimension, $R_{1}$, is given by the expression:

$$
R_{1}=N-\Phi+1
$$

where $N$ is the number of components of the system, and $\Phi$ is the total number of different phases existing in the neighboring phase regions (NPRs). The relationship between $R_{1}$ and the dimension of the "boundary," $R_{1}^{\prime}$, between two NPRs is:

$$
R_{1}^{\prime}=R_{1}+P_{\mathrm{c}}, \text { if } R_{1}=0 ; \text { or } R_{1}^{\prime}=R_{1}+P_{\mathrm{c}}-1, \text { for } R_{1} \geq 1
$$

where $P_{\mathrm{c}}$ is the number of common phases coexisting in NPRs.

Using the above relationships to the $\beta$ - and $\alpha$-TCPss phase regions in Fig. 1, the value $R_{1}^{\prime}=0$ is obtained for the dimension of the "boundary" between both phase regions, which corresponds to a point, instead the line represented in the figure. Thus, the "boundary" between $\beta$ - and $\alpha$-TCPss cannot be a line.

However, Palatnik-Landau's CRPR is fulfilled if the existence of a biphasic region between the $\beta$ - and $\alpha$-TCPss monophasic regions is considered. In such intermediate region, $\beta$ - and $\alpha$-TCPss phases must coexist, and values of $R_{1}^{\prime}=1$, corresponding to a line, are obtained when the previous analysis is repeated for the "boundaries" between the $\beta$-TCPss and $\beta+\alpha$-TCPss and be-

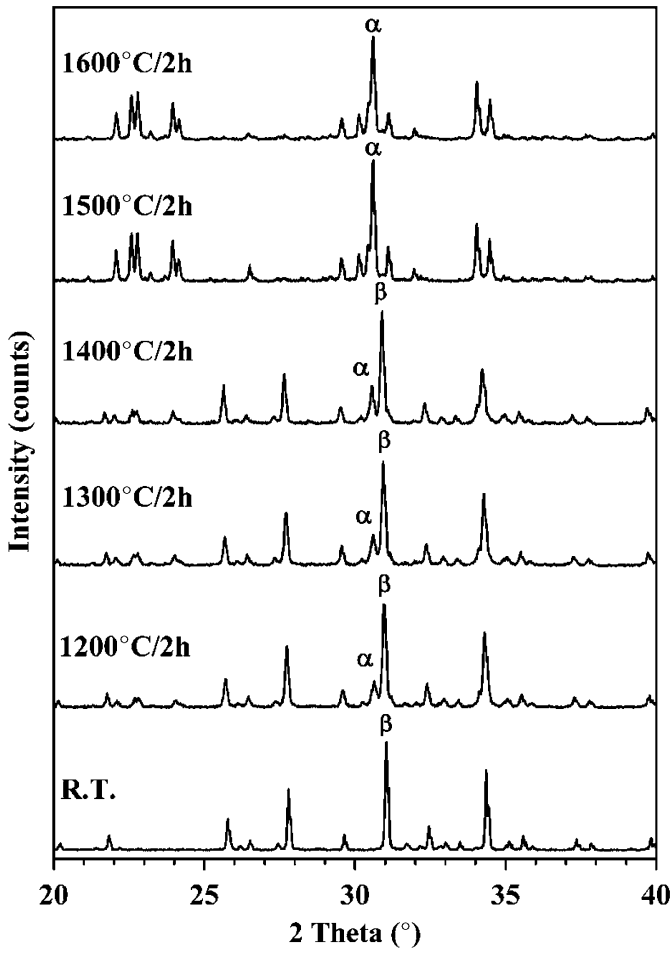

Fig. 4. X-ray diffraction patterns of Mg-doped tricalcium phosphate at room temperature (RT) and after heating at several temperatures for $2 \mathrm{~h}$ (heating and cooling rates: $10^{\circ} \mathrm{C} / \mathrm{min}$ ).

tween the $\alpha$-TCPss and $\beta+\alpha$-TCPss regions. Experimental results confirming the above thermodynamic reasoning are presented below.

The transformations $\beta \rightarrow \alpha$ and $\alpha \rightarrow \alpha^{\prime}$ in Mg-free TCP precursor were studied by high-temperature ND. The evolution of the normalized intensities of peaks with Miller indexes (202) of $\beta$-TCP (JCPDS card no. 9-169), (111) of $\alpha$-TCP (JCPDS card

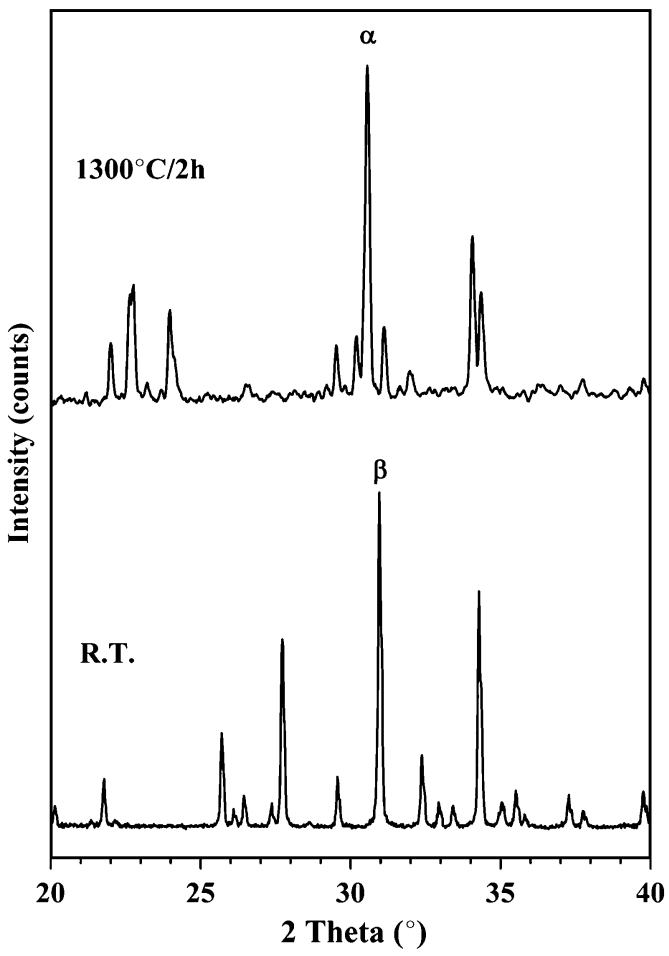

Fig. 5. X-ray diffraction patterns of $\mathrm{Mg}$-free tricalcium phosphate after heating at $900^{\circ}$ and $1300^{\circ} \mathrm{C}$ for $2 \mathrm{~h}$ (heating and cooling rates: $\left.10^{\circ} \mathrm{C} / \mathrm{min}\right)$. 

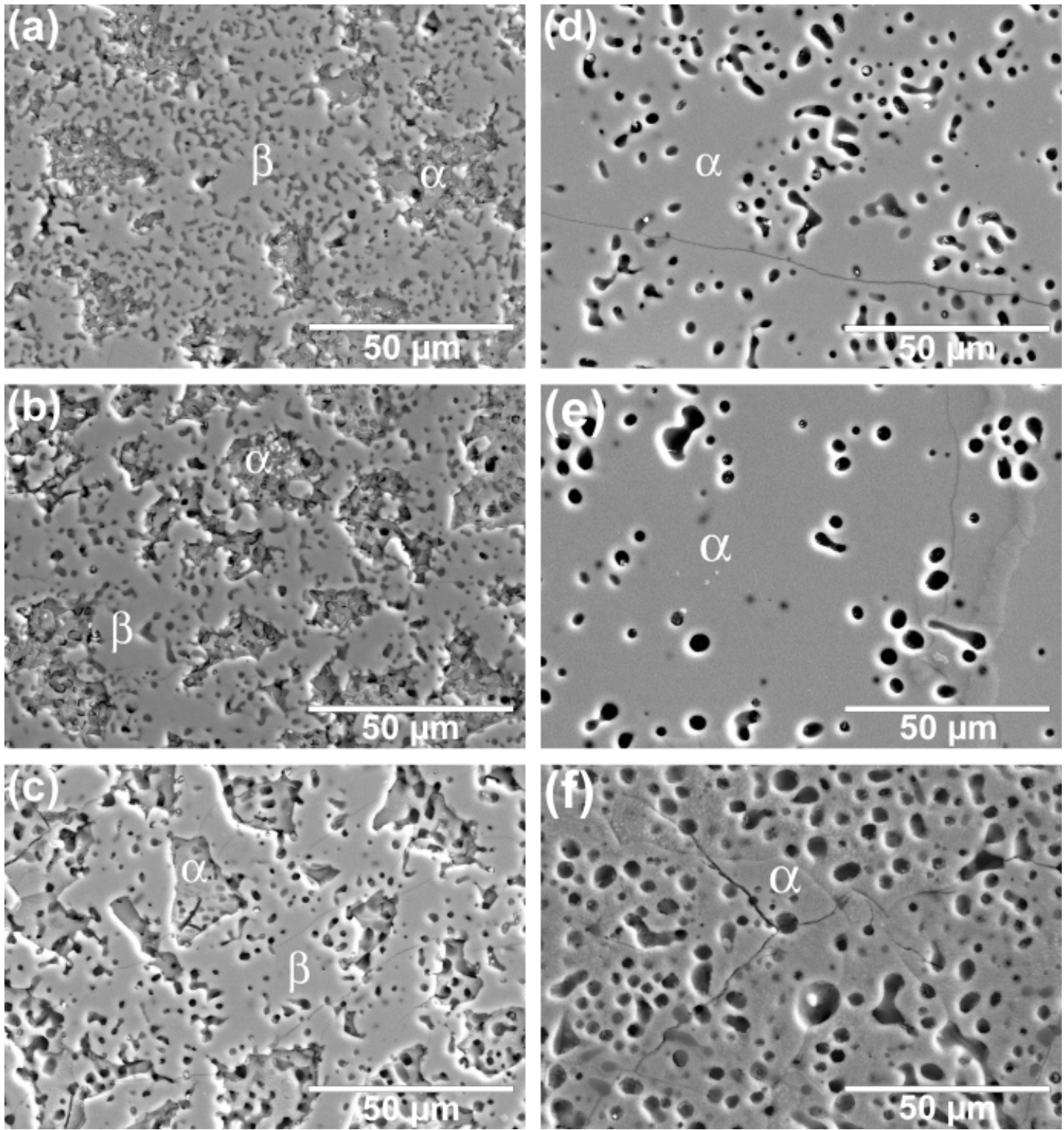

Fig. 6. Surface micrographs (field emission scanning electron microscope ) of polished and etched samples of Mg-doped tricalcium phosphate (TCP) (a-e) and Mg-free TCP (f), treated at various temperatures: (a) $1200^{\circ} \mathrm{C}$, (b and f) $1300^{\circ} \mathrm{C}$, (c) $1400^{\circ} \mathrm{C}$, (d) $1500^{\circ} \mathrm{C}$, and (e) $1600^{\circ} \mathrm{C}$.

no. 9-348), and (060) of $\alpha^{\prime}-\mathrm{TCP}^{17}$ with temperature are presented in Fig. 2. At room temperature the Mg-free TCP precursor consisted only of Ca-deficient apatite and no other diffraction peaks than those of poorly crystallized apatite (not presented in Fig. 2, JCPDS card no. 9-432) could be observed. $\beta$-TCP crystallized around $780^{\circ} \mathrm{C}$ at the expense of the Ca-deficient apatite decomposition. The first evidence of $\alpha$-TCP formation was detected at $\sim 1115 \pm 10^{\circ} \mathrm{C}$, and practically at the same temperature the signal corresponding to $\beta$-TCP disappeared. This suggests a well-defined transition temperature, which is in agreement with thermodynamic data ${ }^{18}$ and with PalatnikLandau's CRPR, considering a monocomponent system $(\mathrm{N}=1)$. From $\sim 1115 \pm 10^{\circ} \mathrm{C}, \alpha-\mathrm{TCP}$ is the only stable phase up to $\sim 1465 \pm 5^{\circ} \mathrm{C}$, at which temperature the $\alpha \rightarrow \alpha^{\prime}$ transformation takes place. During the subsequent cooling $\alpha^{\prime}$-TCP reverts to $\alpha$-TCP at the same temperature, which remains down to room temperature.

On the other hand, the evolution of the normalized intensities of the selected ND peaks of $\beta-, \alpha-$, and $\alpha^{\prime}-$ TCP phases with temperature, during heating and cooling, for Mg-doped TCP is shown Fig. 3. On heating from room temperature $\beta$-TCP was the only crystalline phase originally present and remained stable up to $\sim 1220 \pm 10^{\circ} \mathrm{C}$. The $\beta \rightarrow \alpha$ transformation starts at this temperature and both phases coexist up to $\sim 1365 \pm 5^{\circ} \mathrm{C}$, when the $\beta$ phase disappears. From this temperature up to $\sim 1480 \pm 5^{\circ} \mathrm{C}$ only the $\alpha$ phase remains, the temperature at which it starts to transform in $\alpha^{\prime}$. On cooling, the reversion of $\alpha^{\prime}$ - to $\alpha$-TCP takes place again at $\sim 1480 \pm 5^{\circ} \mathrm{C}$. Below $\sim 1480 \pm$

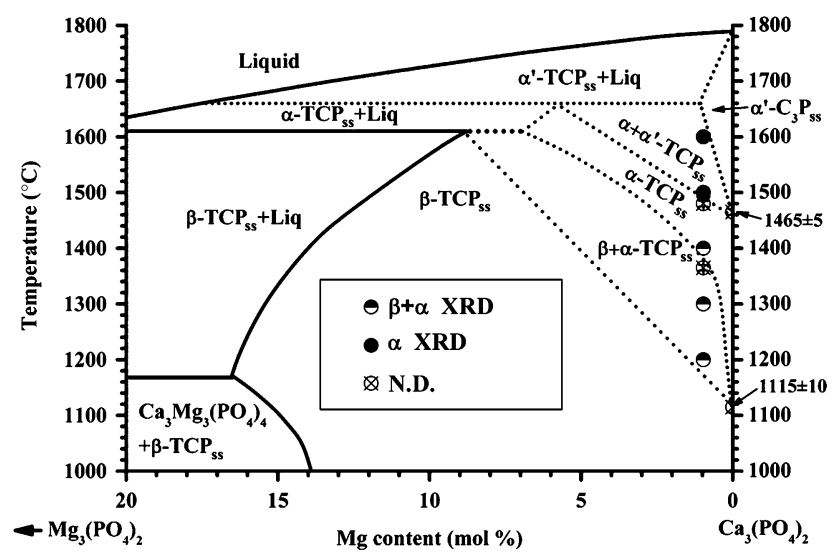

Fig. 7. Tentative phase equilibrium diagram of the tricalcium phosphate-rich region of the system $\mathrm{Mg}_{3}\left(\mathrm{PO}_{4}\right)_{2}-\mathrm{Ca}_{3}\left(\mathrm{PO}_{4}\right)_{2}$, after this work. 
$5^{\circ} \mathrm{C}, \alpha$-TCP is the only crystalline phase and remains stable down to room temperature. These results show that $\beta$ - and $\alpha$-TCP phases coexist in the range of temperatures between $\sim 1220 \pm 10^{\circ}$ and $\sim 1365 \pm 5^{\circ} \mathrm{C}$, and similarly $\alpha$ - and $\alpha^{\prime}$-TCP exist together at $\sim 1480 \pm 5^{\circ} \mathrm{C}$. $\alpha$-TCP does not revert to $\beta$-TCP when cooled at $5^{\circ} \mathrm{C} / \mathrm{min}$ under the observed $\beta \rightarrow \alpha$ transition temperature of $\sim 1220 \pm 5^{\circ} \mathrm{C}$. This fact is consistent with the reconstructive character of the $\beta \leftrightarrow \alpha$ transformation $^{7}$ and makes the numerous synthetic routes described in the literature to prepare pure $\alpha$-TCP invalid, where quenching is proposed as a way to "freeze" the high temperature polymorph of TCP. ${ }^{14,19}$

In fact, the existence of a temperature range where the two polymorphs, $\beta$ - and $\alpha$-TCP, coexist was firstly stated by Gibson et al. ${ }^{19}$ who attributed the phenomenon to nonequilibrium conditions, instead of the occurrence of a biphasic equilibrium region as claimed in this work.

The temperature range corresponding to this biphasic region is strongly influenced by the degree of substitution of $\mathrm{Ca}$ by $\mathrm{Mg}$ atoms in the TCP network.

In accordance with the results showed in Figs. 2 and 3, the temperature corresponding to the beginning of the transformation $\beta \rightarrow \alpha$ is shifted from $\sim 1115 \pm 10^{\circ}$ to $\sim 1220 \pm 10^{\circ} \mathrm{C}$ with the substitution of $0.97 \pm 0.05$ at. $\%$ of $\mathrm{Ca}$ by $\mathrm{Mg}$ in TCP. Moreover, the above transformation proceeds at a definite temperature in the absence of $\mathrm{Mg}$ substitution whereas in $\mathrm{Mg}$-doped TCP there is a temperature range where $\beta$ - and $\alpha$-TCP coexist in equilibrium. Similarly, the temperature at which the transformation $\alpha \rightarrow \alpha^{\prime}$ begins is displaced from $\sim 1465 \pm 5^{\circ} \mathrm{C}$ for $\mathrm{Mg}$-free up to $\sim 1480 \pm 5^{\circ} \mathrm{C}$, for $\mathrm{Mg}$-doped TCP and $\alpha$ - and $\alpha^{\prime}$-TCP must occur simultaneously in a temperature interval for $\mathrm{Mg}$-doped TCP, according to the previous thermodynamic considerations.

$\mathrm{X}$-ray diffraction patterns of Mg-doped and Mg-free TCPs heated at different temperatures and cooled at room temperature are shown in Figs. 4 and 5. In Mg-doped TCP (Fig. 4) $\alpha$ - and $\beta$-phases coexist after heating at $1200^{\circ}, 1300^{\circ}$, and $1400^{\circ} \mathrm{C} . \alpha$-TCP is the only crystalline phase detected in samples of $\mathrm{Mg}$-doped TCP treated at $1500^{\circ}$ and $1600^{\circ} \mathrm{C}$.

On the other hand, Mg-free TCP transforms totally into $\alpha$-TCP by heating at temperatures as low as $1300^{\circ} \mathrm{C}$ (Fig. 5). These results are consistent with the findings of high-temperature ND discussed above.

SEM micrographs (back-scattered electrons) of polished specimens of Mg-doped and Mg-free TCPs, sintered at different temperatures, are shown in Fig. 6. Two clearly distinct kinds of grains were observed in the micrographs of $\mathrm{Mg}$-doped specimens sintered at temperatures between $1200^{\circ}$ and $1400^{\circ} \mathrm{C}$ (Figs. 6(a)-(c)). During acid etching, $\alpha$-TCPss grains are more attacked than those of $\beta$-TCPss because of the larger solubility of the former. In Figs. 6(a)-(c) both phases, $\alpha$ - (more attacked) and $\beta$-TCPss, are observed. However, as expected from the previous results of ND and X-ray diffraction, no differential attack is observed in the micrographs of Figs. 6(d) and (e), corresponding to the temperatures of $1500^{\circ}$ and $1600^{\circ} \mathrm{C}$, respectively, where only the $\alpha$-TCPss phase exists. Furthermore, the area related to the $\alpha$ phase grows at the expense of the area of $\beta$-TCPss by increasing temperature treatment from $1200^{\circ}$ to $1400^{\circ} \mathrm{C}$.

Besides, the micrograph of $\mathrm{Mg}$-free TCP sintered at $1300^{\circ} \mathrm{C}$ (Fig. 6(f)) exhibits an evenly attacked surface consisting only of one phase i.e., $\alpha$-TCPss.

In the light of the results discussed above, a tentative phase equilibrium diagram for the TCP-rich zone of the $\mathrm{M}_{3} \mathrm{P}-\mathrm{C}_{3} \mathrm{P}$ system is proposed (Fig. 7), which is in agreement with the preceding experimental findings, with thermodynamic considerations and Palatnik-Landau's CRPR.

According to it, a biphasic region, where $\beta$ - and $\alpha$-TCPss coexist, separates the fields of $\beta$ - and $\alpha$-TCPss. Similarly, another biphasic region, where $\alpha$ - and $\alpha^{\prime}$-TCPss exist together lies in between the $\alpha$-TCPss and $\alpha^{\prime}$-TCPss fields.

Owing to the $\beta \rightarrow \alpha$ transition is reconstructive and a large activation energy barrier needs to be surpassed to the reverse $\alpha \rightarrow \beta$ transformation occurs, quenching is not required to retain the pure $\alpha$ phase, it is only needed to reach an appropriate temperature inside the field of $\alpha$-TCPss and keep it for a period of time enough to complete the $\beta \rightarrow \alpha$ transformation.

Finally, the new proposed system (Fig. 7) indicates clearly the way of synthesizing pure Mg-doped $\beta$ - or $\alpha$-TCPss as well as controlled mixtures of both polymorphs. On the other hand, it also expands the route to obtain bioceramics of the mentioned pure phases with improved mechanical properties. For instance, highly dense pure phase $\beta$-TCPss ceramics can be obtained by sintering at temperature as high as $1500^{\circ} \mathrm{C}$, depending on the level of $\mathrm{MgO}$ doping, as can be seen in Fig. 7. Similar reasoning is valid to obtain dense pure phase $\alpha$-TCPss by sintering over $1600^{\circ} \mathrm{C}$. Currently, the authors are working in these directions.

\section{Conclusions}

A tentative phase equilibrium diagram for the TCP-rich zone of the $\mathrm{Mg}_{3}\left(\mathrm{PO}_{4}\right)_{2}-\mathrm{Ca}_{3}\left(\mathrm{PO}_{4}\right)_{2}$ system is proposed, where two new biphasic fields: $\beta+\alpha$-TCPss, and $\alpha+\alpha^{\prime}$-TCPss exist. The proposed system is consistent with the experimental findings, with thermodynamic considerations and Palatnik-Landau's CRPR.

Because the $\beta \rightarrow \alpha$ transition is of reconstructive type, the reverse $\alpha \rightarrow \beta$ transformation would require surpassing a large activation energy barrier to proceed. This indicates that quenching is not required to retain the pure $\mathrm{Mg}$-doped $\alpha$-TCP phase, it is only needed to reach a temperature inside the field of $\alpha$-TCPss and to keep it for a period of time enough to complete the $\beta \rightarrow \alpha$ transformation.

Pure phase $\beta$ - and $\alpha$-TCPss ceramics as well as controlled mixtures of $\beta+\alpha$-TCPss may be obtained by adequate thermal treating and controlling the amount of $\mathrm{Mg}$ present in the precursors used.

The proposed system also expands the route to obtain mechanically strengthened bioceramics of the mentioned phases.

\section{Acknowledgments}

The authors wish to acknowledge the assistance of the local contact, Dr. David Martin, during the setup of the experiment at $\mathrm{D}_{1} \mathrm{~B}$, Institut Laue-Langevin, Grenoble, France, and the contribution of Dr. M. A. G. Aranda in offering valuable suggestions during the course of the experiment.

This work is dedicated to the memory of Prof. Michael R. Anseau.

\section{References}

${ }^{1}$ J. C. Elliot, Structure and Chemistry of the Apatites and Other Calcium Orthophosphates. Elsevier Science B. V., Amsterdam, 1994.

2. M. J. Buerger, "The Rôle of Temperature in Mineralogy," Am. Mineral., 33 [3-4] 101-21 (1948).

${ }^{3}$ M. J. Buerger, "Crystallographic Aspects of Phase Transformations"; pp. 183-211 in Phase Transformations in Solids, Edited by R. Smoluchowski, J. E. Meyer, and W. A. Weyl. John Wiley \& Sons Inc., New York, 1951.

${ }^{4} \mathrm{M}$. Bohner, "Calcium Orthophosphates in Medicine: From Ceramics to Calcium Phosphate Cements," Injury, 31 [Suppl. D] 37-47 (2000).

${ }^{5}$ S. V. Dorozhkin, "Calcium Orthophosphates," J. Mater. Sci., 42, 1061-95 (2007).

${ }^{6} J$. Ando, "Phase Diagrams of $\mathrm{Ca}_{3}\left(\mathrm{PO}_{4}\right)_{2}-\mathrm{Mg}_{3}\left(\mathrm{PO}_{4}\right)_{2}$ and $\mathrm{Ca}_{3}\left(\mathrm{PO}_{4}\right)_{2}-\mathrm{CaNaPO}_{4}$ Systems,' Bull. Chem. Soc. Jpn., 31 [2] 201-5 (1958).

${ }^{7}$ R. Enderle, F. Götz-Neunhoeffer, M. Göbbels, F. A. Müller, and P. Greil, "Influence of Magnesium Doping on the Phase Transformation Temperature of $\beta$-TCP Ceramics Examined by Rietveld Refinement," Biomaterials, 26, 3379-84 (2005).

${ }^{8}$ L. S. Palatnik and A. I. Landau, "Topologicheskoe issledovanie diagramm ravnovesiya mnogokomponentnykh geterogennykh sistem i ikh neuzlovykh sechenii pri pomoshchi pravila o soprikasayushchikhsya oblastyakh razdeleniya .1," Zh. Fiz. Khim., 30 [11] 2399-411 (1956).

${ }^{9}$ L. S. Palatnik and A. I. Landau, "The Topological Investigation of Equilibrium Diagrams of Multi-Component Heterogenous Systems and of their Knotless Sections with the Aid of the Contiguous Separation Regions Law.2," Zh. Fiz. Khim., 31 [2] 304-14 (1957).

${ }^{10}$ L. S. Palatnik and A. I. Landau, Phase Equilibria in Multicomponent Systems. Holt, Rinehart and Winston Inc., New York, 1964.

${ }^{11}$ H. C. Yeh, "IV.V Law of Adjoining Phases"; pp. 193-94 in Theory, Principles and Techniques of Phase Diagrams, Vol. I, Edited by A. M. Alper. Academic Press, New York, 1970 
${ }^{12}$ M. Zhao, Q. Wan, L. Song, and S. Feng, "Comparison of the Boundary Theory with the Contact Rule of Phase Regions and Gupta's Method," Sci. China $B, 49$ [1] 12-20 (2006).

${ }^{13}$ R. Famery, N. Richard, and P. Boch, "Preparation of $\alpha$ - and $\beta$-Tricalcium Phosphate Ceramics, with and without Magnesium Addition," Ceram. Int., 20, 327-36 (1994)

${ }^{14}$ N. Jinlong, Z. Zhenxi, and J. Dazong, "Investigation of Phase Evolution During the Thermochemical Synthesis of Tricalcium Phosphate," J. Mater. Syn. Proc., 9 [5] 235-40 (2001).

${ }^{15}$ K. Itatani, T. Nishioka, S. Seike, F. S. Howell, A. Kishioka, and M. Kinoshita, "Sinterability of Beta-Calcium Orthophosphate Powders Prepared by Spray-Pyrolysis," J. Am. Ceram. Soc., 77 [3] 801-5 (1994).
${ }^{16}$ H.-S. Ryu, H.-J. Youn, K. S. Hong, B.-S. Chang, C.-K. Lee, and S.-S. Chung, "An Improvement in Sintering Property of $\beta$-Tricalcium Phosphate by Addition of Calcium Pyrophosphate," Biomaterials, 23, 909-14 (2002).

${ }^{17}$ A. H. De Aza, L. Contreras, S. De Aza, X. Turrillas, P. N. De Aza, and D. Martin, Phase Transformation of Tricalcium Phosphate, Grenoble, Institut LaueLangevin; Report nr CRG-932 2004.

${ }^{18}$ I. Barin, F. Suert, E. Schultze-Rhonhof, and W. Shu Sheng, Thermomechanical Data of Pure Substances. Verlagsgesellschaft, New York, 1989.

${ }^{19}$ I. R. Gibson, M. Akao, S. M. Best, and W. Bonfield, "Phase Transformation of Tricalcium Phosphates Using High Temperature X-Ray Diffraction"; pp. 173-76 in 9th International Symposium on Ceramics in Medicine Proceedings, Edited by T. Kokubo, T. Nakamura, and F. Miyaji. Pergamon Press, Otsu, Japan, 1996. 